Pacific Journal of Mathematics

RATIONAL FORMAL GROUP LAWS

BERT COLEMAN AND FRANCIS OISIN MCGUINN 


\section{RATIONAL FORMAL GROUP LAWS}

\section{Robert F. Coleman and Francis Oisin McGuinness}

In this paper we determine the rational formal groups defined over a field of characteristic zero. This answers a question originally posed by Robert MacPherson.

While one can answer this question using Weil's theorem which asserts that every birational group is birationally isomorphic to an actual algebraic group [W1], below we give an elementary argument using methods similar to those used in $[\mathbf{C}]$.

THEOREM. Every rational formal group law over an algebraically closed field $K$ of characteristic zero is of the form

$$
L^{-1} G(L(x), L(y))
$$

where $G(x, y)$ is either $x+y$ or $x+y+x y$ and $L$ is a linear functional transformation over $K$ such that $L(0)=0$.

One deduces easily from this that

COROLLARY. The rational formal group laws over a field $K$ of characteristic zero are the rational functions

$$
(x+y+c x y) /(1-d x y)
$$

where $c$ and $d$ are elements of $K$. Moreover, this formal group is rationally isomorphic to $x+y$ over $K$ if $c^{2}-4 d=0$ and to $x+y+x y$ over $K\left(\sqrt{\left(c^{2}-4 d\right)}\right)$ otherwise.

Proof of theorem. Recall that now $K$ is algebraically closed. Suppose $F(x, y)$ is a rational formal group.

Let $\omega=d x / F_{2}(x, 0)$ and $g(x)=F(x, x)$ (the rational function giving multiplication by 2 on $F$ ). Then $\omega$ and $g$ satisfy the hypothesis of the following proposition:

Proposition. Suppose $\omega \in K(x) d x$ and $g \in K(x), \omega \neq 0$, $\operatorname{ord}_{0} \omega$ $=0, g(0)=0$ and $g^{*} \omega=2 \omega$. Then $\omega=L^{*}(d x)$ or $L^{*}(c d x /(x+1))$ 
where $L$ is a linear fractional transformation defined over $K$ such that $L(0)=0$ and $c \in K^{*}$.

Proof. Let $Y$ denote the set of poles and $Z$ the set of zeros of $\omega$. It follows from the hypothesis that $g^{-1} Y=Y$ and $g^{-1} Z=Z$.

The equation $g^{*} \omega=2 \omega$ implies that

$$
\sum \operatorname{ord}_{Q} g^{*} \omega=\sum \operatorname{ord}_{Q} \omega
$$

where the sums run over $Q \in Y=g^{-1} Y$. Suppose $Q \in \mathbb{P}^{1}(K)$. Then we also have the formula

$$
\sum \operatorname{ord}_{P} g^{*} \omega=\operatorname{deg}(g) \cdot \operatorname{ord}_{Q} \omega+\left(\operatorname{deg}(g)-\# g^{-1}(Q)\right)
$$

where the sum runs over $P \in g^{-1}(Q)$. Suppose now $Q$ is a pole of $\omega$. The right-hand side of this formula is less than or equal to $\operatorname{ord}_{Q} \omega$. Hence the last two formulas imply that

$$
\operatorname{deg}(g) \cdot \operatorname{ord}_{Q} \omega+\left(\operatorname{deg}(g)-\# g^{-1}(Q)\right)=\operatorname{ord}_{Q} \omega
$$

for all1 $Q \in Y$. This occurs for a given $Q \in Y$ iff $\operatorname{deg}(g)=1$ or $\operatorname{ord}_{Q} \omega=-1$ (in which case $\# g^{-1}(Q)=1$ ).

Suppose first that $\operatorname{deg}(g)=1$ and $\omega$ has a pole of order greater than one. Since $g^{*} \omega=2 \omega$, no iterate of $g$ is the identity. As $g(0)=0$ it follows that there exists exactly one non-zero point fixed by some iterate of $g$. Since $g^{-1} Y=Y, g^{-1} Z=Z$ and $\operatorname{ord}_{0} \omega=0$, we see that $\omega$ has only one pole and no zeros. It follows that $\omega=L^{*}(d x)$ for some linear fractional transformation $L$ which we may assume vanishes at the origin.

Suppose now that $\omega$ has only simple poles. If $Q$ is a pole of $\omega$ we know that $g^{-1}(Q)$ consists of exactly one point, $P$ say, and we have the formula

$$
\operatorname{Res}_{P} g^{*} \omega=\operatorname{deg}(g) \operatorname{Res}_{Q} \omega
$$

by a local computation. Since $g^{*}(\omega)=2 \omega$, this becomes

$$
\operatorname{Res}_{P} \omega=(\operatorname{deg}(g) / 2) \operatorname{Res}_{Q} \omega .
$$

Now we know that $g^{-1} Y=Y$. Hence, there exists a $Q$ in $Y$ and a positive integer $n$ such that $\{Q\}=g^{-n}(Q)$. By iterating the previous equation we deduce that

$$
(\operatorname{deg}(g) / 2)^{n} \operatorname{Res}_{Q} \omega=\operatorname{Res}_{Q} \omega .
$$

Hence, as $\operatorname{Res}_{Q} \omega \neq 0$ and $\operatorname{deg}(g) \in \mathbb{Z}_{>0}, \operatorname{deg}(g)=2$. 
The facts that $g^{-1} Y=Y$ and $g^{-1} Z=Z$ imply that the zeros and poles of $\omega$ lie among the branch points of $g: \mathbb{P}^{1} \rightarrow \mathbb{P}^{1}$. Since $g$ has degree 2 it has only two branch points. Since $\omega$ is not equal to zero, has only simple poles and its residues sum to zero it must have exactly two poles and no zeros. Hence $\omega=L^{*}(c d x /(x+1))$ for some linear fractional transformation $L$ and some constant $c \in K^{*}$. Since $\operatorname{ord}_{0} \omega=0$, we may assume $L(0)=0$. This proves the proposition.

The theorem follows from the proposition noting that $F(x, y)=$ $L^{-1} G(L(x), L(y))$ where $G(x, y)=x+y$ if $\omega=L^{*}(d x)$ and $G(x, y)=x+y+x y$ if $\omega=L^{*}(c d x /(x+1))$.

REMARK. The only place in the above argument where the algebraic closedness of $K$ was used in a serious manner was in the last step which required finding a linear fractional transformation which moved one pole of $\omega$ to 0 and the other to $\infty$.

\section{REFERENCES}

[C] R. Coleman, One dimensional algebraic formal groups, Pacific J. Math., 122 (1986), 35-41.

[W] A. Weil, On algebraic groups of transformations, Amer. J. Math., 77 (1955), 355-391.

Received November 6, 1988 and in revised form January 17, 1989.

UNIVERSITY OF CALIFORNIA

BERKELEY, CA 94720

FORDHAM UNIVERSITY

BRONX, NY 10458 



\section{PACIFIC JOURNAL OF MATHEMATICS EDITORS}

V. S. VARADARAJAN

(Managing Editor)

University of California

Los Angeles, CA 90024-1555-05

Herbert Clemens

University of Utah

Salt Lake City, UT 84112

THOMAS ENRIGHT

University of California, San Diego

La Jolla, CA 92093

\section{R. FINN}

Stanford University

Stanford, CA 94305

HermanN FlaschKa

University of Arizona

Tucson, AZ 85721

VAUGHAN F. R. JoNES

University of California

Berkeley, CA 94720

STEVEn KeRCKHOFF

Stanford University

Stanford, CA 94305
C. C. MOORE

University of California

Berkeley, CA 94720

MARTIN SCHARLEMANN

University of California

Santa Barbara, CA 93106

Harold STARK

University of California, San Diego La Jolla, CA 92093

\section{ASSOCIATE EDITORS}

R. ARENS

E. F. BECKENBACH (1906-1982)
B. H. NeumanN

\section{SUPI}

UNIVERSITY OF ARIZONA

UNIVERSITY OF BRITISH COLUMBIA

CALIFORNIA INSTITUTE OF TECHNOLOGY

UNIVERSITY OF CALIFORNIA

MONTANA STATE UNIVERSITY

UNIVERSITY OF NEVADA, RENO

NEW MEXICO STATE UNIVERSITY

OREGON STATE UNIVERSITY
F. WolF
K. YoshidA
(1904-1989)

UNIVERSITY OF OREGON UNIVERSITY OF SOUTHERN CALIFORNIA

STANFORD UNIVERSITY

UNIVERSITY OF HAWAII

UNIVERSITY OF TOKYO

UNIVERSITY OF UTAH

WASHINGTON STATE UNIVERSITY

UNIVERSITY OF WASHINGTON 


\section{Pacific Journal of Mathematics}

Vol. 147, No. $1 \quad$ January, 1991

Mark S. Ashbaugh, Evans Malott Harrell, II and Roman Svirsky, On minimal and maximal eigenvalue gaps and their causes $\ldots \ldots \ldots \ldots \ldots 1$

Robert Coleman and Francis Oisin McGuinness, Rational formal group

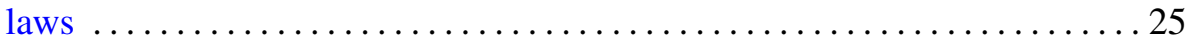

Jacek M. Cygan and Leonard Frederick Richardson, $D$-harmonic distributions and global hypoellipticity on nilmanifolds ...........29

Satya Deo and Kalathoor Varadarajan, Some examples of nontaut

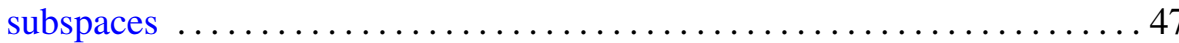

Maria Fragoulopoulou, Automatic continuity of *-morphisms between

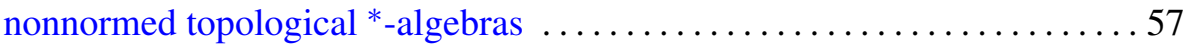

Stephen J. Gardiner, Removable singularities for subharmonic functions . . . 71 Herbert Paul Halpern, Victor Kaftal and László Zsidó, Finite weight projections in von Neumann algebras $\ldots \ldots \ldots \ldots \ldots \ldots \ldots \ldots \ldots \ldots$

Telemachos E. Hatziafratis, Explicit $\bar{\partial}$-primitives of Henkin-Leiterer kernels on Stein manifolds

Ka Hin Leung, A construction of an ordered division ring with a rank one

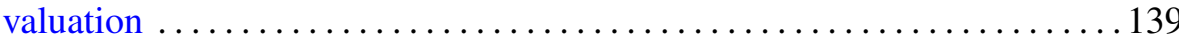

Christopher K. McCord, Nielsen numbers and Lefschetz numbers on solvmanifolds

Katsuro Sakai and Raymond Y. T. Wong, Manifold subgroups of the homeomorphism group of a compact $Q$-manifold

Caroline Perkins Sweezy, $L$-harmonic functions and the exponential square class 